\title{
LA CONVENCIÓN DE LA HAYA DEL 23 DE NOVIEMBRE DE 2007 SOBRE EL COBRO INTERNACIONAL DE ALIMENTOS CON RESPECTO A LOS NIÑOS Y OTRAS FORMAS DE MANUTENCIÓN DE LA FAMILIA*
}

\section{Nuria GONZÁLEZ MARTÍN**}

Una vez más estamos ante un supuesto de familia internacionalizada, en donde el trasiego transfronterizo, familias multinacionales en aumento, propicia el incremento exponencial de demandas por alimentos de menores y de otros miembros dependientes familiares.

El número de alimentos, relacionados con niños, no sufragados —al igual que los alimentos en beneficio de otros miembros dependientes de la familia - es apabullante, no es un caso que se da de manera aislada ni excepcional. Los procedimientos internacionales en materia de alimentos, caracterizados por su lentitud, complejidad, costo y falta de eficiencia han propiciado la elaboración de una convención en el ámbito internacional, en el marco de la Conferencia de La Haya, que tiene como portaestandarte, precisamente, paliar o acabar con esta situación que deriva en carencias de todo tipo en el medio familiar y que detona una debilidad de posibilidades en muchos ámbitos, en el que podríamos destacar, por supuesto, la nutrición o la educación, por no ir más allá de una multitud de implicaciones.

La Conferencia de La Haya de Derecho Internacional Privado es una organización internacional compuesta por 107 países, dedicada a unificar reglas de DIPr. Una organización que expresó, en su 17a. sesión, que tenía como objetivo convertirse en un centro mundial al servicio de la cooperación internacional judicial y administrativa en materia de derecho privado y de manera muy destacada en el ámbito de la protección de la infancia.

* Agradezco las notas proporcionadas, con relación a la participación y reservas proyectadas por México - a la doctora María Elena Mansilla y Mejía - delegada mexicana en la Conferencia de La Haya.

** Doctora en derecho; investigadora en el Instituto de Investigaciones Jurídicas de la UNAM; directora del Boletín Mexicano de Derecho Comparado; miembro de la Academia Mexicana de Ciencias. 
Así las cosas, y con esta tendencia muy acentuada, la Conferencia de La Haya, en su 21o. sesión, cumplimentó la Convención de La Haya del 23 de noviembre de 2007 sobre el Cobro Internacional de Alimentos con Respecto a los Niños y otras Formas de Manutención de la Familia (en adelante Convención sobre Alimentos de 2007). ${ }^{1}$ En este momento, destacamos que dicha Convención será complementaria a los convenios, de ámbito internacional, de la Conferencia de La Haya con relación a las obligaciones alimenticias y en concreto a los convenios del 24 de octubre de 1956 sobre Ley Aplicable a las Obligaciones Alimenticias con Relación a los Hijos, y del 15 de abril de 1958 sobre Reconocimiento y Ejecución de Decisiones en Materia Alimenticia con Relación a los Hijos, ambos de la década de los cincuenta, y que fueron sustituidos en la década de los setenta por el Convenio del 2 de octubre de 1973 sobre Ley Aplicable a las Obligaciones Alimenticias y la Convención del 2 de octubre de 1973 sobre Reconocimiento y Ejecución de Decisiones Relativa a las Obligaciones Alimenticias. Además, en el ámbito de Naciones Unidas, también complementa al Convenio de Nueva York del 20 de junio de 1956 sobre Obtención de Alimentos en el Extranjero. ${ }^{2}$ En el ámbito regional destaca la Convención Interamericana sobre Obligaciones Alimentarias de 15 de julio de 1989, en el marco de la CIDIP-IV. ${ }^{3}$

Todas las convenciones mencionadas, tanto de ámbito internacional como regional, tienen entre sus objetivos el facilitar los trámites para hacer efectivo el derecho de alimentos, cuando demandante (acreedor) y demandado (deudor) residan en diferentes países, estableciendo los procedimientos necesarios en orden a lograr el pago de esta obligación;

1 Una Convención que tuvo un total de cuarenta y dos documentos preliminares, que abarcan de 1995 a 2007, véase $w w w . h c c h . n e t$; no obstante, hay que hacer la observación de que toda esta normativa convencional fue discutida a partir de 1992 y fue a raíz de los principios adoptados por la Convención de Naciones Unidas sobre los Derechos de los Niños de 1989, en la cual se insta a los países a tomar medidas apropiadas para garantizar el pago de alimentos a los menores.

2 Los Estados signatarios de este instrumento, dentro de la esfera de la Organización de Estados Americanos (OEA) son: Argentina, Barbados, Bolivia, Brasil, Colombia, Cuba - no es Estado miembro de la OEA - Chile, República Dominicana, Ecuador, El Salvador, Guatemala, Haití, México, Surinam y Uruguay.

3 Destacamos entre los Estados miembros de la Organización de Estados Americanos (OEA) que han suscrito dicha Convención Interamericana: Argentina, Belice, Bolivia, Brasil, Colombia, Costa Rica, Ecuador, Guatemala, Haití, México, Panamá, Paraguay, Perú, Uruguay y Venezuela. 
cuestión permeada de las mejores intenciones, pero que aún está pendiente de su efectividad.

En la sesión diplomática, celebrada del 5 al 23 de noviembre de 2007, a la que asistieron delegados de sesenta y ocho Estados, la Comunidad Europea y otras organizaciones representadas por un total de 268 expertos, se firmó concretamente el 23 de noviembre, el Acta Final de la Sesión, en presencia de los representantes del Ministerio de Asuntos Exteriores de los Países Bajos, embajadores de los Estados miembros y otros representantes diplomáticos. Junto con la firma del Acta Final de esta Convención se dio la firma de la propia Convención sobre Alimentos de 2007 y su Protocolo Adicional por parte de los Estados Unidos de América.

Entre los antecedentes más inmediatos con relación a la elaboración de esta nueva Convención y su Protocolo Adicional firmado en 2007 tenemos que destacar la creación de una Comisión Especial para el Cobro de Alimentos en el ámbito internacional, que comenzó a trabajar en 2003 con reuniones anuales. ${ }^{4}$

Las bases que dieron pauta a este nuevo instrumento convencional constan en el informe elaborado en abril de 2003 por William Ducan ${ }^{5}$ y que se pueden resumir en las siguientes:

1. Prever, como uno de sus elementos esenciales, disposiciones en materia de cooperación administrativa.

2. Ser completo e inspirarse en los mejores aspectos de los documentos ya existentes.

3.Tener en cuenta, para las necesidades futuras, el desarrollo ya obtenido por una diversidad de países, con énfasis en las cuestiones relativas al progreso de las técnicas de información.

4. Estar estructurada de forma que se combine la máxima eficacia con la flexibilidad necesaria para el mayor número posible de ratificaciones.

4 Cinco reuniones de la Comisión Especializada (2003, 2004, 2005, 2006 y 2007) y una conferencia diplomática, en noviembre 2007, en la cual la Convención fue aprobada.

5 Documento preliminar núm. 3, abril de 2003, "Vers un nouvel instrument mondial sur le recouvrement intenational des aliments envers les enfants et d'autres membres de la famille", http://www.hcch.net; véase, también, Duncan, William, "The New Hague Convention of 23 November 2007 on the International Recovery of Child Support and Other Forms of Family Manintenance”, International Family Law (Issue 1). 
La conclusión que se desprende del documento es, básicamente, que la materia ha sido regulada de una manera excesivamente compleja, con poca eficacia, con costos elevados y un proceso lento. La justificación de esta situación descrita se basa en la instauración de un sistema muy burocratizado que no supo explorar las nuevas tecnologías de información y tampoco atendía el número creciente de personas que demandaban este servicio. El objetivo perseguido a través de la Comisión Especial instaurada en 2003, como decimos, fue precisamente preparar un documento que posibilite la obtención internacional de alimentos para menores y otros miembros de la familia, con reglas más eficientes y reforzando la cooperación con otros instrumentos internacionales relacionados.

Así, la Convención aprobada tiene una base fundamental en la cooperación jurídica internacional, en el que incorpora distintas metodologías que han funcionado en otras convenciones de La Haya y, además, da a las autoridades centrales un importante poder de coordinación. ${ }^{6}$

En definitiva, la Convención, desde su preámbulo, marca las pautas que han motivado la elaboración de un convenio con estas características, y así se expresa que "lo que se necesita es un sistema que produzca resultados y que sea accesible, rápido, eficiente, rentable, sensible y justo". En esa tónica, podemos concretar y/o reiterar, dada la importancia del mismo, que el Convenio establece un completo sistema de cooperación entre las autoridades encargadas de los alimentos con respecto a los niños. No sólo se atiende con procedimientos efectivos, una situación de desamparo que sufre el menor y otros miembros de la familia, sino que indirectamente beneficia al contribuyente, sujeto pasivo en el que finalmente revoca la carga fiscal que supone la no satisfacción de las obligaciones privadas.

Con relación a la estructura de la Convención sobre Alimentos de 2007, tenemos que tiene un total de sesenta y cinco artículos, distribuidos en 9 capítulos, bajo el siguiente esquema:

- Preámbulo.

- Capítulo I: Objeto, ámbito de aplicación y definiciones (artículos 1-3).

- Capítulo II: Cooperación administrativa (artículos 4-8).

6 Araujo, Nadia de, Directo internacional privado. Teoria y prática brasileira, 4a. ed., Río de Janeiro, Renovar, 2008, pp. 510 y ss. 
- Capítulo III: Solicitudes para la intermediación de las autoridades centrales (artículos 9-17).

- Capítulo IV: Restricciones al procedimiento (artículo 18).

- Capítulo V: Reconocimiento y ejecución (artículos 19-31).

- Capítulo VI: Ejecución por el Estado requerido (artículos 32-35).

- Capítulo VII: Organismos públicos (artículo 36).

- Capítulo VIII: Disposiciones generales (artículos 37-57).

- Capítulo IX: Disposiciones finales (artículos 58-65).

- Anexo I: Formulario de transmisión en virtud del artículo 12 (2).

- Anexo II: Formulario de recepción en virtud del artículo 12 (3).

Como venimos expresando, en las distintas reuniones diplomáticas que fueron sustentando el Convenio de Alimentos de 2007 se determinaron una serie de actualizaciones con la finalidad de cubrir el marco jurídico internacional de la obligación alimentaria, dando forma al mencionado Convenio, así como a su Protocolo adicional.

Entre los problemas más discutidos en la preparación de la Convención destacaron:

1. La edad máxima para recibir alimentos (artículo 2o.).

2. El grado de parentesco hasta el que se extendería la obligación alimenticia (artículo 2o.).

3. La instrumentalización del cobro de alimentos a través de dos vías (artículos 4o.-13).

4. El acceso efectivo a la justicia (artículos 14-17).

5. Los medios de coacción para obtener el pago de alimentos (artículos 19-27).

En cuanto al primero de los cuestionamientos mencionados (la edad), se determinó que la obligación de proporcionar alimentos se fijaría a la persona menor de 21 años.

En México es de considerarse respecto a este tema, las disposiciones constitucionales y aquéllas contenidas en los códigos civiles. La Constitución Política (CPEUM) expresa, en su artículo 4o., párrafos 6 y 7, el derecho que tienen los niños de recibir alimentos, así como de la obligación de los ascendientes, tutores y custodios:

Los niños y las niñas tienen derecho a la satisfacción de sus necesidades de alimentación, salud, educación y sano esparcimiento para su desarrollo integral. 
Los ascendientes, tutores, custodios tienen el deber de preservar estos derechos. El Estado proveerá lo necesario para propiciar el derecho a la dignidad de la niñez y el ejercicio pleno de sus derechos.

Es de mencionarse que la mayoría de edad se alcanza con los 18 años de acuerdo con el artículo 34 de la CPEUM.

Considerando las disposiciones del derecho civil destacamos el contenido del artículo 303 del Código Civil Federal (CCF), el cual establece que "los padres están obligados a dar alimentos a sus hijos".

Es importante, además, hacer mención al cese de la obligación alimentaria cuando el acreedor alimentario haya cumplido la mayoría de edad. El artículo 306 del CCF establece la obligación de los parientes colaterales hasta el cuarto grado a proporcionar alimentos a los menores mientras éstos llegan a la edad de dieciocho años, es decir, que aquellos que tengan el deber de proporcionar alimentos a un menor de edad, se liberan de acuerdo con el CCF de este compromiso cuando el menor de edad deje de serlo, ya que se considera que éste deja de tener incapacidad natural (artículo 450, fracción I). Es necesario dejar claro que en caso de que el acreedor alimentario se encuentre en el supuesto del artículo 450 fracción II, no importa la edad, ya que el deber jurídico persiste hasta que el acreedor alimentario deje de tener esta incapacidad jurídica. ${ }^{7}$

En este sentido, destacamos que la Suprema Corte de Justicia de la Nación en México ha establecido el criterio de que la obligación alimentaria "por concepto de educación" no se extingue necesariamente cuando los acreedores alimentarios alcanzan la mayoría de edad. ${ }^{8}$

Para ir en congruencia con la legislación nacional e internacional, México prevé realizar una reserva de acuerdo con el artículo 2.2. Si México establece la mayoría de edad a los 18 años y ésta es la que marca el límite para recibir alimentos, con las excepciones marcadas, y la Con-

7 Respecto de las causas por las que la obligación alimentaria cesa, debemos considerar el contenido del artículo 320 del CCF, el cual establece: "Cesa la obligación de dar alimentos: I. Cuando el que la tiene carece de medios para cumplirla; II. Cuando el alimentista deja de necesitar los alimentos; III. En caso de injuria, falta o daño graves inferidos por el alimentista contra el que debe prestarlos; IV. Cuando la necesidad de los alimentos dependa de la conducta viciosa o de la falta de aplicación al trabajo del alimentista, mientras subsistan estas causas; V. Si el alimentista, sin consentimiento del que debe dar los alimentos, abandona la casa de éste por causas injustificables".

8 Contradicción de tesis 169/2006-PS, 1a. Sala, Semanario Judicial de la Federación y su Gaceta, novena época, t. XXVI, julio de 2007, p. 32. 
vención establece el derecho para los menores de 21 años, el Estado mexicano debe prever una reserva en el sentido comentado.

Con respecto a la segunda cuestión marcada, el grado de parentesco hasta el que se debe extender la obligación alimenticia, debemos de considerar al sujeto activo y al pasivo.

De esta manera, encontramos que la obligación alimentaria de acuerdo con la Convención se extiende para las personas que tengan entre sí un parentesco ya sea por consanguinidad, afinidad o civil, además de aquellas que sean consideradas como incapaces, lo anterior de acuerdo con los artículos 2.3 y 2.4 de la Convención.

México, con relación a esta cuestión, a través de su legislación autónoma, artículos 302, 307, 301, 305, párrafo 2, y 306 del Código Civil Federal, en ese orden, extiende el derecho a recibir alimentos a la concubina, a la ex esposa, el hijo adoptivo, los parientes colaterales hasta el cuarto grado y a los familiares en estado de vulnerabilidad. ${ }^{9}$

Por lo que hace a los deudores alimentarios, la legislación civil extiende este deber jurídico hasta el cuarto grado, partiendo de la regla de que los parientes más cercanos excluyen a los más lejanos para responder de esta obligación.

Por otro lado, con relación a la instrumentalización del cobro de alimentos, la Convención contempla dos vías de petición de alimentos: la vía administrativa y la vía judicial. La solicitud de alimentos se puede presentar a la autoridad administrativa quien decidirá si es ella quien los

9 No queremos dejar pasar la ocasión para subrayar que México al legislar en su Código Civil del Distrito Federal la violencia familiar, y, concretamente, con la reforma que se instauró a través del Decreto que reforma diversos artículos del Código Penal y del Código Civil, ambos para el Distrito Federal, publicado en la Gaceta Oficial del Distrito Federal, del 17 de enero de 2007, incorporó en su artículo 323 quáter, párrafo III, la violencia doméstica y así la define como: "los actos que implican el control de los ingresos, el apoderamiento de los bienes propiedad de la otra parte, la retención, menoscabo, destrucción o desaparición de objetos, documentos personales, bienes, valores, derechos o recursos económicos de la pareja o de un integrantes de la familia. Así como, el incumplimiento de las obligaciones alimentarias por parte de la persona que de conformidad con lo dispuesto en éste Código tiene obligación de cubrirlas". Definitivamente, esta reforma marca un paso de gran trascendencia, al invocar como causa de violencia familiar, la denominada violencia económica en la que se engloba, sin lugar a dudas, el incumplimiento de la obligación alimenticia. Este dato reitera y confirma la necesidad de regular jurídicamente una situación que está sucediendo de manera rutinaria. 
tramita o remite al procedimiento judicial; México, en este sentido, tiene contemplada ambas vías.

Por lo que respecta a la vía administrativa, misma que es gratuita, se encuentra regulada en los artículos 4o.-13 de la Convención en el que destaca la incorporación de dos formularios en los anexos I y II, a través de los cuales se transmita, por un lado, y se reciba por el otro, la información necesaria con respecto a la obligación alimentaria.

La vía judicial se prevé, fundamentalmente, para contemplar aquellos países que no disponen de la vía administrativa y que, por el contrario, sí tienen contemplado la vía judicial mediante la asistencia jurídica gratuita.

Con relación al mencionado acceso efectivo a la justicia que se encuentra regulado en los artículos 14 a 17 de la Convención en comento, ésta se establece que se prestará en los mismos términos que a los nacionales, es decir, será gratuito cuando se pruebe su necesidad y será oneroso en los demás casos.

El artículo 14, dedicado a la asistencia jurídica, fue adoptado con una declaración de aquellos países que así lo desearan, para analizar las condiciones económicas de los niños y o de los padres, en la concesión del auxilio jurídico.

En ese orden de ideas, si por una lado tenemos el procedimiento judicial y, por el otro lado, no se instrumentaliza el posterior reconocimiento y ejecución de las resoluciones de manera gratuita, difícilmente se podrá dar cobertura a la denominada competencia judicial internacional indirecta, es decir, al reconocimiento y ejecución de la sentencia, en el entendido que quien solicita alimentos carece de los medios para cubrir los gastos. En principio, la gratuidad se considera sólo para los menores de 21 años, salvo que los Estados realicen una declaración respecto a la extensión de dicho beneficio, sin olvidar, como acabamos de expresar, que se puede proporcionar la asistencia gratuita mediante la prueba de su necesidad.

En definitiva, el artículo 20, relativo al reconocimiento de las decisiones extranjeras, fija reglas para un procedimiento más rápido en el reconocimiento y ejecución de la decisión extranjera, con las observaciones vertidas anteriormente, pero permite una declaración del país para que continúe con su sistema interno. 
Otro rasgo destacable de la Convención sobre Alimentos de 2007 es el establecimiento de medios de coacción para dar cumplimiento a la obligación alimentaria, establecido en el artículo 34.

México prevé en el artículo 317 del Código Civil Federal la posibilidad de asegurar los alimentos mediante diversos medios, entre los que destacamos la hipoteca, prenda, fianza, el depósito, los cuales deben ser los suficientes para cubrir los alimentos.

Es importante, destacar, por otra parte, que durante todo el articulado del Convenio sobre Alimentos de 2007, se presenta un respeto al principio de igualdad de las partes; asimismo, se contemplan las figuras de orden público y fraude a la ley.

Con relación a la ley aplicable, después de amplios debates al respecto, se decidió su separación de la Convención y de ahí su derivación a un Protocolo Adicional. De este Protocolo podemos destacar:

1. El carácter universal, lo cual permite su aplicación para aquellos países no firmantes (artículo 2o.).

2. Prevaleció como punto general de conexión la residencia habitual del acreedor, es la aplicación, en definitiva, de la ley del foro (artículo 3o.).

3. Reglas especiales, con relación a la ley aplicable en el caso de alimentos para niños con otras personas, y de los hijos con respecto a sus padres (artículo 4o.).

4. Se extiende una regla diversa a la pronunciada en el citado artículo 3o., con relación a la ex esposa, en el cual dicho artículo no se aplica si hubiere más contacto con el lugar de la última residencia común.

5. El reenvío fue excluido, como regla separada.

6. La posibilidad de la autonomía de las partes en designar una ley aplicable para los alimentos, dentro de límites muy estrechos.

7. Cuida su ámbito de aplicación y el orden público.

8. Establece una norma de carácter material, al determinar que las cuestiones de ley aplicable a los alimentos debe de tomar en cuenta las necesidades del acreedor y las posibilidades del deudor (artículo 14).

Destacamos por otro lado, el artículo 57, que impone a los Estados la obligación de informar sobre su derecho interno, una solución más que 
loable que posibilitará la ayuda en su aplicación y evitará costos de abogados o especialistas en la materia. ${ }^{10}$

La Convención se abrió a la firma sólo para los Estados miembros al celebrarse la vigésima primera sesión, y también podrán firmarla los Estados no miembros que participaron en ella como es el caso mencionado de los Estados Unidos de América. Su Protocolo Adicional, con su carácter universal, prevé también su aplicación a aquellos países no firmantes. La Convención entrará en vigor con la segunda ratificación.

Como conclusión podemos expresar que, junto con los convenios de La Haya existentes en la materia, en donde incluimos el de Protección de los Niños, Sustracción de Menores, Adopción Internacional y por supuesto esta Convención sobre Alimentos de 2007, amén de los convenios en la materia en el ámbito regional, estamos provistos de herramientas, definitivamente eficientes, reales y prácticas de protección a la minoridad y a todos aquellos miembros de la familia que reclamen este derecho al alimento. Ya no debe de haber excusas que detonen un incumplimiento del cobro de alimentos; el conocimiento de la normativa internacional, en este caso, y el aterrizaje a la práctica cotidiana junto con la voluntad política y la voluntad de todos aquellos operadores jurídicos que se ven inmersos en la eficiencia de la misma, ya no es un reclamo, es un imperativo.

No estamos ajenos al supuesto de que aún puede haber deficiencias, si así lo queremos ver con rigurosidad, en cuestiones como: definiciones clave de este nuevo instrumento, tales como obligaciones alimenticias; determinación de los supuestos para que se aplique el instrumento internacional; sujetos objeto del instrumento (personas menores de 21 años, personas que mantienen vínculos consanguíneos o parentales y en qué grado de consanguineidad, cónyuges, ascendientes, descendientes, etcétera); en la definición de un procedimiento expedito, o en la determinación de las autoridades intervinientes, requisitos del reclamo, fundamentos mínimos que debe acompañar la solicitud y procedimiento a seguir; cuestiones relativas a la sustanciación del reclamo: pruebas de paternidad o filiación, validez de los instrumentos justificantes del reclamo, definición de las instancias intervinientes en la solicitud; definición de términos y plazos para resolver la solicitud; garantías del debido proceso para la parte solicitante y también para la parte demandada; garantías de eje- 
cución de la medida; implantación de mecanismos financieros para la transferencia de recursos pecuniarios a bajo costo en esta materia; facilitación de información financiera y laboral del demandado por las instancias administrativas y privadas para garantizar la ejecutoriedad de la petición; medidas provisionales ante la petición de obligaciones alimentarias; y por acotar esta numeración, simplemente la compatibilidad entre el nuevo instrumento internacional y la legislación nacional vigente en la materia. ${ }^{11}$

Toda esta relación, en el mejor de los casos, abruma por no decir que desanima, pero precisamente el fin o el objetivo de la academia, desde la teoría y la práctica, es detectar o llamar la atención sobre todas las cuestiones que ameritan un extremo cuidado. No nos desviamos de las expresiones de entusiasmo y aliento manifestadas en líneas anteriores ante una nueva y, pensamos, magnífica Convención sobre Alimentos de 2007. Tenemos claridad en los avances y en los pasos de gigante que ha dado este nuevo instrumento internacional, tan sólo pedimos "no bajar la guardia" ante la práctica diaria y las situaciones particulares de cada caso y en cada ente.

11 Informe Especial del Instituto Interamericano del Niño, www.iin.org.uy. 